\title{
Production of Extracellular Enzymes, Antimicrobial and other Agriculturally Important Metabolites by Fungal Endophytes of Litsea glutinosa (Lour.) C.B.Rob. a Medicinal Plant
}

\author{
Abhinesh Madasi ${ }^{1}$ (D) Aruna Ajmeera ${ }^{1}$ (D) , Gudepu Renuka ${ }^{2}$ (D), \\ Bhavani Vemireddy ${ }^{1}$ (D) and Krishna Reddy Vanteru ${ }^{1 *}$ (D) \\ ${ }^{1}$ Department of Botany, Toxicology laboratory, Kakatiya University, Warangal - 506 009, Telangana, India. \\ ${ }^{2}$ Department of Microbiology, Pingle Government Degree College for Women, Waddepally, \\ Hanamkonda - 506 002, Telangana, India.
}

\begin{abstract}
The present paper deals with the endophytic fungi of Litsea glutinosa, a medicinal plant highly valued in Ayurvedic system. A total of 21 fungal endophytes were extracted from different parts of the plant. The following eight species viz, Aspergillus oryzae, A. terreus, Curvularia sp, Fusarium oxysporum, Gliocladium solani, Penicillium citrinum, Trichoderma viride and Verticillium dahliae were selected for testing the production of secondary metabolites including hydrolytic enzymes. All the eight endophytic fungal species produced amylase, cellulase, protease and lipase. Except for Curvularia species, others did not elaborate laccase. All the test fungi produced antibacterial and antifungal metabolites; however, the crude extracts exhibited poor antimicrobial activity. The present endophytic fungi also produced IAA, ammonia and phosphate solubilizing substances. They were also capable to produce IAA with or without adding the tryptophan. An affect was also made to assess the influence of crude extracts on the root growth of maize seedlings. These studies revealed the enhancement effect of extracts on root growth. Based on these observations, discussions and conclusions were made.
\end{abstract}

Keywords: Endophytic fungi, Litsea glutinosa, Secondary metabolites, Biological activities

*Correspondence: vkreddyku@gmail.com; +91 9885511837

(Received: June 29, 2021; accepted: September 30, 2021)

Citation: Madasi A, Ajmeera A, Renuka G, Vemireddy B, Vanteru KR. Production of Extracellular Enzymes, Antimicrobial and other Agriculturally Important Metabolites by Fungal Endophytes of Litsea glutinosa (Lour.) C.B.Rob. a Medicinal Plant. J Pure Appl Microbiol. 2021;15(4):2317-2328. doi: 10.22207/JPAM.15.4.56

(C) The Author(s) 2021. Open Access. This article is distributed under the terms of the Creative Commons Attribution 4.0 International License which permits unrestricted use, sharing, distribution, and reproduction in any medium, provided you give appropriate credit to the original author(s) and the source, provide a link to the Creative Commons license, and indicate if changes were made. 


\section{INTRODUCTION}

Endophytic fungi means the fungi grow within the plant tissues without causing any damage to their host for at least a part of their life cycle ${ }^{1}$. "They colonize internal plant tissues of healthy leaves, stem, bark, root, fruit, flower and seeds. The relationship between the endophyte and its host plant may range from latent pathogenesis to symbiosis" ${ }^{2 \prime}$. Endophytic fungi are mostly affiliated to ascomycetes and anamomorphic fungi ${ }^{3}$.

Endophytes colonize all most all plants, but the choice of the host plant colonized depends on fungal species. Many medicinal plants are reported as harbour endophytes ${ }^{4}$. Endophytes from medicinal plants posses the ability to protect their host from pathogens and also confer tolerance against various difficult conditions by secretion of bioactive compounds. An endophyte can produce many bioactive metabolites. The production of various natural products by the endophytes with greater bioactivity has received notable attention ${ }^{5}$. Bioactive metabolites of endophytes have important applications in medicine, agriculture and industries ${ }^{6}$. So many antifungal and antibacterial compounds have been extracted from endophytic fungi ${ }^{7}$. These metabolites have different structures like alkaloids, benzopyramones, chinones, flavonoids, phenolic acids, quinines, terpenoids, tetralones and xanthones ${ }^{8}$. The bioactive secondary metabolites show several biological properties as anticancer, antimicrobial, antioxidant, immunomodulators and anti-inflammatory etc. As a result, the researchers are showing greater interest on fungal endophytes from medicinal plants to find out novel compounds.

Fungal endophytes also can produce various extracellular enzymes like amylase, cellulase, lipase, protease and laccase etc. Enzymes produced from the endophytes act as efficient biocatalysts for industrial applications ${ }^{9}$ and they play a significant role in protecting the host plant in many ways. The fungal endophytes may enhance plant growth. For example by the ammonia production and phytoharmones like indole -3 - acetic acid (IAA) ${ }^{10}$ which helps in cell differentiation and cell elongation in plants and by the phosphate solubilization.

Litsea glutinosa (Lour.) C.B.Rob (Family:
Lauraceae). A traditional medicinal plant, (fig: 1) contains high valued therapeutic properties. Since ancient days, Indian people use the bark and leaves of the tree in the form of decoctions to cure diarrhea and dysentery ${ }^{11}$. This plant may host a rich diversity of endophytes, with potentials to produce bioactive compounds with biotechnological interest. However, existence and role of fungal endophytes of L.glutinosa are not yet explored. The main aim of the present study was isolation and identification of fungal endophytes from L.glutinosa, to assess extracellular enzymes and antimicrobial compounds, and also to assay the ability of ammonia production, solubilization of phosphate and IAA production from the selected fungal endophytes.

\section{MATERIAL AND METHODS Sample collection}

Fungal endophytes were isolated from various parts of the L.glutinosa, growing in different forest regions (Table 1) of Warangal district, Telangana state, India. Healthy and mature plants were carefully chosen for sampling. The plant parts viz., roots, leaves and stems were collected (In sterile polythene bags) and brought to the laboratory then processed within 24- 48 hours for isolation of fungal endophytes.

\section{Isolation of fungal endophytes}

Fungal endophytes were isolated by using the methods which were employed by Petrini $(1986)^{12}$ and Hallman et al. (2007) ${ }^{13}$. After the sample collection, the plant samples were washed with tap water and then trimming was made with sterile scalpel under sterilized conditions ${ }^{14}$. Samples were surface sterilized with $70 \%$ alcohol for 1 minute and with sodium hypochlorite ( $\mathrm{NaOCl}$ ) or mercuric chloride $\left(\mathrm{HgCl}_{2}\right)$ for 30 seconds.

Then samples were cleaned with double sterile distilled water for 1 minute then allowed to dry on filter paper. After complete drying, 4 segments were inoculated on potato dextrose agar (PDA) plates supplemented with streptomycin and incubated at $27 \pm 2^{\circ} \mathrm{C}$ for 5 to 7 days. Pure cultures isolated from the segments were sub cultured time to time on PDA slants then stored at $4^{\circ} \mathrm{C}$ with proper labeling.

\section{Identification of fungal endophytes}

From the well grown fungal cultures, microscopic slides were made by using lactophenol 
cotton blue and then examined under the light and fluorescent microscopes to take the microphotographs for the identification. By analyzing the colony morphology, surface texture, pigmentation and spore morphology and by using standard manuals, the endophytic fungi were identified up to species level ${ }^{15}$.

\section{Extracellular enzyme production}

The production of enzymes by endophytic fungi was qualitatively assayed by using Hankin and Anagnostakis method $(1975)^{16}$. The role of extracellular enzymes by endophytic fungi was examined by placing $5 \mathrm{~mm}$ mycelia plugs on PDA and incubating at $25^{\circ} \mathrm{C}$ for one week. After incubation period at room temperature, the zone arround the fungal colony was measured as enzyme activity. All assays were analysed in triplicate.

The fungi were grown on GYP agar medium ( glucose $-1 \mathrm{~g}$, yeast extract $-0.1 \mathrm{~g}$, peptone $-0.5 \mathrm{~g}$, agar $-16 \mathrm{~g}$, distilled water- IL) along with $0.2 \%$ soluble starch. After incubation period, the plates with fungal colonies were loaded with $1 \%$ iodine in $2 \% \mathrm{KI}$. The clear zone surrounded by the fungal colony was taken as positive for enzyme activity of amylase. In cellulase activity, the fungi were grown on GYP agar medium with $0.5 \%$ Carboxy Methyl Cellulose. When incubation completes and fungal growth takes place then the plates were loaded with $0.2 \%$ Congo red and removed excess stain with $1 \mathrm{M} \mathrm{NaCl}$ for 15 minutes. Yellow colour appearance around the fungal colony or media turns to red colour indicates positive cellulase activity. Whereas in lipase activity, the fungi were grown on peptone agar medium (peptone $-10 \mathrm{~g}$, $\mathrm{NaCl}-5 \mathrm{~g}, \mathrm{CaCl} 2.2 \mathrm{H} 2 \mathrm{O}-0.1 \mathrm{~g}$, agar $-16 \mathrm{~g}$, distilled water - 1L; $\mathrm{pH}-6.0$ ) along with sterilized $1 \%$ Tween 20 separately added to the medium. After incubation, a precipitate or a clear zone around the fungal colony indicates the positive lipase activity. In proteolytic activity, the fungi were grown on GYP agar medium supplemented with $0.4 \%$ gelatin was used. Separately sterilized $8 \%$ gelatin solution in water was added to the medium @ $5 \mathrm{ml}$ per $100 \mathrm{ml}$. After the incubation period, plates were sprayed with aqueous ammonium

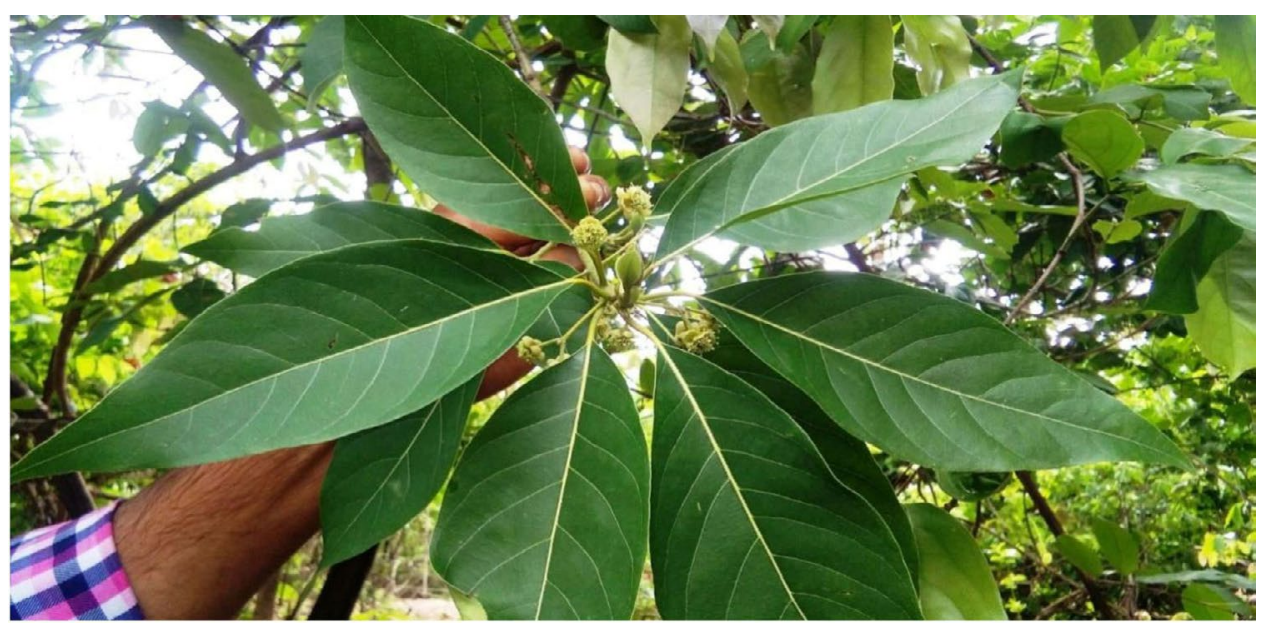

Fig. 1. Litsea glutinosa.

Table 1. Geographical characters of sample collection locations

\begin{tabular}{lccccc}
\hline Location & \multicolumn{2}{c}{$\begin{array}{c}\text { Geographical } \\
\text { co ordinates }\end{array}$} & Altitude & Average rain fall & Average temp. \\
\cline { 2 - 5 } & $\mathrm{N}$ & $\mathrm{E}$ & & \\
\hline Pakal wild life sanctuary & $17^{\circ} 57^{\prime}$ & $7959^{\prime}$ & $225 \mathrm{~m}$ & $500-1225 \mathrm{~mm}$ & 15 to $42^{\circ} \mathrm{C}$ \\
Eturunagaram wild life sanctuary & $18.341^{\circ}$ & $80.33^{\circ}$ & $63-139 \mathrm{~m}$ & $800-1000 \mathrm{~mm}$ & 20 to $43^{\circ} \mathrm{C}$ \\
Erragattu hills, Hasanparthy & $18.0072^{\circ}$ & $79.5584^{\circ}$ & $2725 \mathrm{~m}$ & $217-744 \mathrm{~mm}$ & 35 to $47^{\circ} \mathrm{C}$ \\
\hline
\end{tabular}


sulphate. The unaborbed gelatin will precipitate with ammonium sulphate and absorbed area around the fungal colony appears as a clear zone indicates the positive activity of protease. In the laccase activity, the fungi were grown on GYP Agar medium supplemented with $0.05 \mathrm{~g} 1$ - naphthol $\mathrm{L}-1$, was used. After the incubation period, the colourless medium turns in to blue colour by the oxidation of 1 - naphthol which indicates the positive enzyme activity of laccase.

\section{Assay of anti microbial activity \\ Fungal crude extraction}

Fungal crude extract was prepared using the protocol of Radji et al. (2011) ${ }^{17}$. The selected isolates of fungal endophytes were inoculated in potato dextrose broth (PDB) and incubated at $27 \pm$ ? for 21 days with intermittent shaking. The fungal broth culture was filtered with whatman no. 1 filter paper for a clear filtrate and mycelia and processed for the extraction. Supernatant was extracted with equal volume of organic solvent (chloroform) and the extracts were evaporated with the help of rotary evaporator.

\section{Antimicrobial assay}

Antimicrobial activities of selected fungal crude extracts were done by the agar well diffusion method. The selected pathogenic bacteria and pathogenic fungus were as follows: Staphylococcus aureus, Micrococcus luteus (Gram positive), Klebsiella pneumonia, Salmonella typhi (Gram negative) and a fungus Candida albicans. All theses strains were obtained from the Department of Microbiology Kakatiya University, Warangal, maintained on Sabouraud dextrose agar medium (fungi), nutrient agar medium (Bacteria) and stored at $4^{\circ} \mathrm{C}$.

Bacterial suspensions were standardized to contain approximately $1.5 \times 10^{8} \mathrm{CFU} / \mathrm{ML}$. The bacteria were inoculated on surface of the nutrient agar medium and fungus was inoculated on Sabouraud dextrose agar medium. The dried crude extract from the solvent (chloroform) of 8 different fungal species were dissolved with DMSO and used to assess the antimicrobial activity ${ }^{18}$. $5 \mathrm{~mm}$ diameter wells were made with sterile cork borer in the test media and filled with $20 \mu \mathrm{l}$ of endophytic fungal extract. Positive controls are filled with penicillin, streptomycin, for gram +ve, gram -ve bacteria and ketoconazol for Candida albicans respectively, and DMSO (without fungal extract) was used as negative control. The plates were placed at $4^{\circ} \mathrm{C}$ for $4 \mathrm{hrs}$ and then incubated at $35 \pm 2^{\circ} \mathrm{C}$ and $28 \pm 2^{\circ} \mathrm{C}$ for $24 \mathrm{hrs}$ for bacteria and fungi respectively.

\section{Phosphate solubilization}

Selected fungal spores were inoculated on Pikovskaya's agar medium and inoculated at $28^{\circ} \mathrm{C}$ for proper growth of the hyphae. Phosphate solubilization was assessed by the clear zones around the colonies ${ }^{19}$.

\section{Ammonia production}

The production of ammonia by fungal endophytes was assessed by using the Singh et al. (2014) method ${ }^{20}$. Selected fungal isolates were grown at $28^{\circ} \mathrm{C}$ for $72 \mathrm{hrs}$ in peptone water. To determine the ammonia production $1 \mathrm{ml}$ of Nessler's reagent was added to the peptone broth which contains fungal strains. The change of intensity of colour in to light yellow (minimum) or deep yellow (maximum) indicates the production of ammonia.

\section{IAA production}

For the production of IAA, the isolated strains were screened by subjecting the culture filtrate to calorimetric assay by using Salkowski reagent $\left(300 \mathrm{ml} \mathrm{H}_{2} \mathrm{SO}_{4}, 500 \mathrm{ml}\right.$ distilled water; $\left.15 \mathrm{ml} 0.5 \mathrm{M} \mathrm{FeCl}_{3}\right)^{21}$. Selected fungal isolates were grown in $20 \mathrm{ml}$ Czapek Dox (CD) broth supplemented with $(1 \mathrm{mg})$ or without tryptophan for 10 days at $25^{\circ} \mathrm{C}$. After incubation, at $4^{\circ} \mathrm{C}$ the culture filtrates were centrifuged at $6000 \mathrm{rpm}$ for $10 \mathrm{~min}$. To determine the IAA production, $1 \mathrm{ml}$ of supernatant added with $2 \mathrm{ml}$ Salkowski reagent, then incubated in the dark for 30 minutes. Pink colour development indicates the production of IAA and its optical density values was measured at $530 \mathrm{~nm}$ with spectrophotometer. Amounts of IAA production by the selected fungal endophytes were estimated with the help of plotting standard IAA graph ${ }^{22}$.

\section{Effect of endophytic fungi on root growth}

"The impact of endophytic fungal inoculations on root growth was carried out on maize (Zea mays L.) seedlings. The maize seeds were surface sterilized with $2.5 \%$ sodium hypochlorite for $3 \mathrm{~min}$ and then they were washed with double sterile distilled water for 5 times. The selected strains were inoculated in CD broth for 5 days at $28 \pm 2{ }^{\circ} \mathrm{C}$. Sterilized seeds were incubated in $50 \mathrm{ml}$ of each fungal strain broth medium at 
room temperature for one day. The $C D$ broth which has no fungal strain used as control. After incubation period, the soaked seeds transferred on to sterilized petri dishes, which containing wet filter papers and incubated for 5 days at room temperature in dark and measured growth of the $\operatorname{root}^{23 \prime \prime}$.

All the results were analyzed statistically along with ANOVA and DMRT.

\section{RESULTS}

Isolation and identification of fungal endophytes

In the present study we isolated the endophytes from the aerial parts of the host plant (Table2). A total of 21 fungal endophytes were isolated from 60 plant segments of L.glutinosa. Among them, eight fungal endophytes were selected based on preliminary screenings of the present study. Based on morphological and photomicrographic features (fig: 2 and 3), they were identified as Aspergillus oryzae, A. terreus, Curvularia sp, Fusarium oxysporum, Gliocladium solani, Penicillium citrinum, Trichoderma viride and Verticillium dahliae.

\section{Enzymatic activity}

A critical perusal of the tables 3 and fig 4 reveals that, out of eight selected endophytic fungal species, seven fungal species showed significant enzymatic activity, where as one endophytic fungus, Verticillium dahliae did not show any enzyme activity. According to ANOVA analysis and DMRT the highest enzymatic activity was shown by Trichoderma viride (19.333) with lipase and lowest activity shown by Penicillium citrinum (7.333) and Gliocladium solani (7.333) for amylase and protease respectively. The production of amylase was maximum in Aspergillus terreus (11.667) and lowest was recorded in
Penicillium citrinum (7.333). Trichoderma viride, Fusarium oxysporum, Verticillium dahliae were negative for amylase production. Cellulase activity was maximum in Trichoderma viride (18.667) compared to other endophytic fungi and least amount of cellulase was recorded for Fusarium oxysporum (7.667). Among all tested endophytic fungal strains, Aspergillus oryzae and Curvularia sp (10.667) showed highest protease production and lowest was recorded in Gliocladium solani (7.333). The remaining strains did not produce protease. Lipolytic activity of Trichoderma viride (19.333) was highest in comparison with other endophytic strains and least amount of lipase was recorded for Aspergillus terreus (8.667). None of the test endophytic fungi tested positive for laccase production.

\section{Antimicrobial activity}

In this activity eight endophytic species were tested against bacteria and fungi and results are presented in table 4 and fig 5 . It is evident from the table that all the eight fungal species tested for antimicrobial activity. When compared to the positive control there is no remarkable effect of fungal crude extract on pathogenic organisms. Among the all strains high inhibition zone appeared in Fusarium oxysporum $(27.333 \mathrm{~mm}$ ) against Staphylococcus aureus and low inhibition zone was recorded in Aspergillus oryzae $(0.750$ $\mathrm{mm}$ ) against Micrococcus luteus, but Verticillium dahliae did not show inhibition zone against microbes tested (Table 3). The antimicrobial activity results were compared with control by ANOVA (DMRT) by degree of freedom (df) all the parameters showed the significance and none of the strains were not significant.

Results pertaining to production of IAA by endophytic species are presented in table 5 .

Table 2. Part wise isolation of endophytic fungi from the host plant

\begin{tabular}{lccc}
\hline No. & Code & Plant part & Endophytic fungi isolated \\
\hline 01 & EFLL 105 & Leaves & Aspergillus terrieus \\
02 & EFLS 94 & Stem & Aspergillus oryzae \\
03 & EFLR 36 & Roots & Trichoderma viridae \\
04 & EFLL 156 & Leaves & Gliocladium solani \\
05 & EFLR 92 & Roots & Curvularia sp. \\
06 & EFLB 52 & Bark & Penicillium citrinum \\
07 & EFLR 83 & Roots & Fusarium oxysporum \\
08 & EFL 75 & Leaves & Verticillium dahlia \\
\hline
\end{tabular}


The fungal broth supplemented with tryptophan supported high amount of IAA when compared to fungal broth without tryptophan in all fungal species. In presence of tryptophan, the high amount of IAA was produced by Trichoderma viride (70.333) and the least amount of IAA by Penicillium citrinum (41.333). The high amount of IAA was produced by Trichoderma viride (63.667) and the least amount was recorded for Penicillium citrinum (33.667) in the absence of tryptophan.

From the results presented in table 6 , it is clear that all the test endophytic fungi were able to produce ammonia. However, there is a variation among test fungi. Similarly, except V. dahlia, all the remaining test fungi elaborated the phosphate solubilizing enzymes. It points out the fact that these fungi are important for plant in mobilizing the phosphates.

All the eight fungi under investigation were tested for their efficiency of enhancing the root growth and the results are presented in fig 6 and 7. A critical analysis of the fig 7 reveals that all the endophytic fungal inoculations enhanced root growth more than the control. It may be due to the production of ammonia and IAA. Trichoderma viride inoculations showed maximum root growth followed by Penicillium citrinum, Fusarium oxysporum and Gliocladium solani. Least root growth enhancement was shown by Verticillium dahliae.

\section{DISCUSSION}

Repeated appearance and isolation of a particular fungal strain from the same plant/plant part provides an indication that it is an endophyte. Endophyte occurrence in plants can be examined in stems, leaves, bark, roots and also found in elongating radicles in germinating seeds ${ }^{24,25}$. The plant developmental stages, environmental factors, and geographical locations are also known to
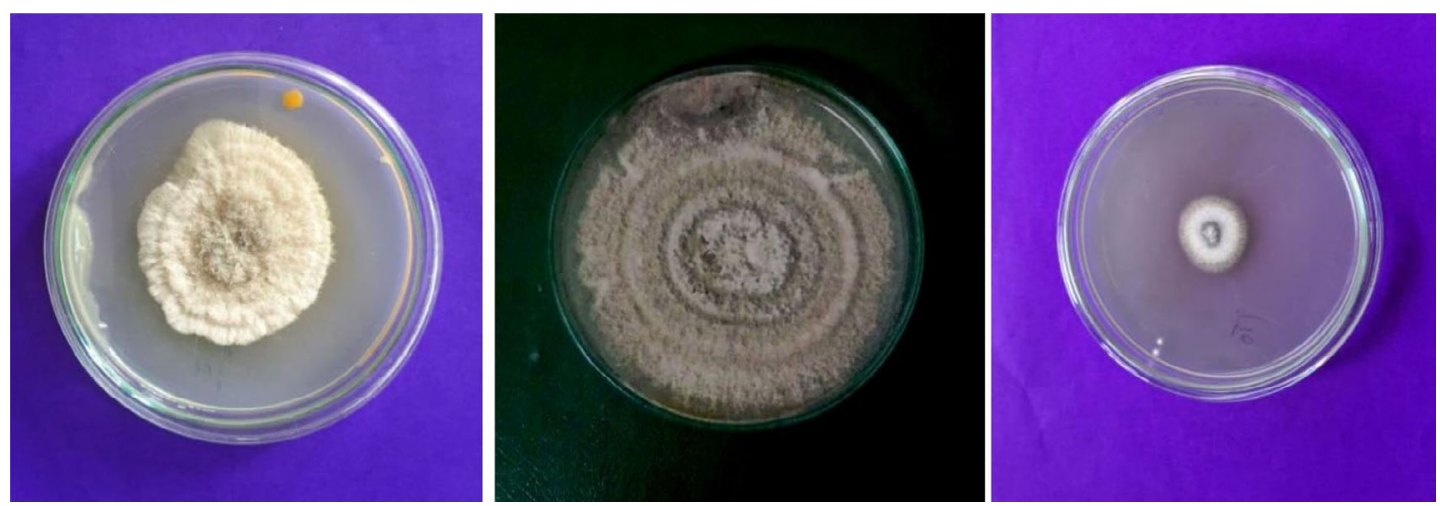

Fig. 2. Colony morphology of endophytic fungi.

(i) Verticillium dahliae

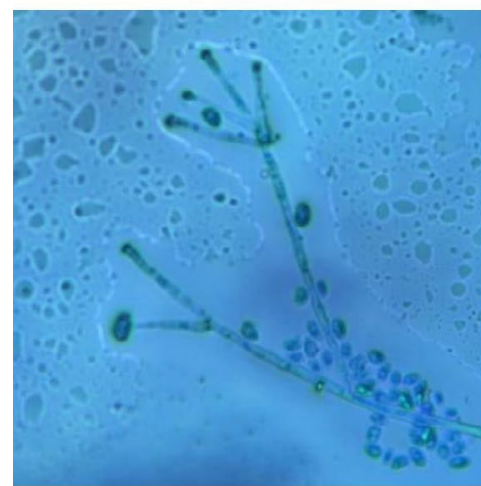

(ii) Gliocladium solani

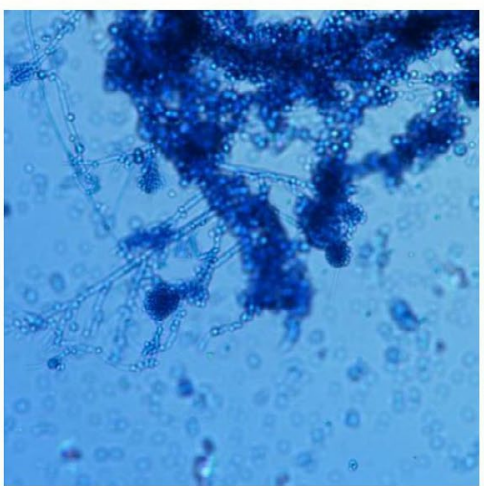

(iii) Fusarium oxysporum

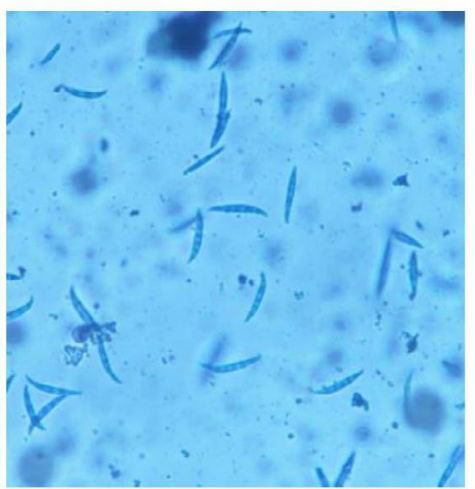

Fig. 3. Photomicrographs of endophytic fungi. 
determine the extent of fungal endophyte diversity in plants ${ }^{26}$. There exists a beneficial relationship between the endophyte and host which can be characterized to the capacity of endophytes to produce a variety of bioactive metabolites ${ }^{27}$. These metabolites are proved to be useful in various human related fields such as agriculture, medicine etc $^{28}$. As such, the intensive research is oriented towards the exploitation of endophytes as a great source of valuable products for commercial purpose ${ }^{29}$. The present investigations were oriented towards the further exploitation of metabolites of endophytes. Medicinal plants are targeted by many investigators. L. glutinosa is a medicinal plant which was using in Ayurvedic treatments. In this study 8 endophytic fungi were frequently associated with various parts of the $L$. glutinosa and tested for the production of various bioactive compounds.

The selected eight fungal endophytes were capable to produce amylase, cellulase, protease and lipase. Except Curvularia species

Table 3. Evaluation of the enzyme activity of endophytic fungi isolated from Litsea glutinosa

\begin{tabular}{|c|c|c|c|c|c|}
\hline \multirow[b]{2}{*}{ Endophytic Fungi } & \multicolumn{5}{|c|}{ Enzymatic activity $(\mathrm{mm})^{2}$} \\
\hline & Amylase & Cellulase & Protease & Lipase & Laccase \\
\hline Aspergillus terrieus & $11.667^{\text {a a a a }}$ & $14.333^{a} a b a b a b$ & $0.000^{\mathrm{a}}$ & $8.667^{c d c d}$ & $0.000^{a b a a}$ \\
\hline Aspergillus oryzae & 10.667 a а а & 12.000 ab ab ab ab & $10.667^{\mathrm{abab}}$ & $10.000^{c c c c}$ & $0.000^{a b a a}$ \\
\hline Trichoderma viridae & $0.000^{c c c c}$ & 18.667 а а а & $0.000^{c d c d}$ & 19.333 а аа а & $0.000^{\mathrm{ab} a \mathrm{a}}$ \\
\hline Gliocladium solani & 11.333 а а а а & $10.333^{a b} b a b a b$ & $7.3333^{b c b c}$ & $0.000^{\text {dede }}$ & $0.000^{a b a a}$ \\
\hline Curvularia sp & $8.333^{\mathrm{bbbb}}$ & $0.000 b c c d b c c$ & $10.667^{\text {a bab }}$ & 0.000 dede & 0.333 а а а \\
\hline Penicillium citrinum & $7.333^{b b b b}$ & 10.000 ab b abc ab & $0.000^{c d c d}$ & $10.000^{c c c c}$ & 0.000 ab a a \\
\hline Fusarium oxysporum & $0.000 \mathrm{cccc}$ & $7.667 a b c b c a b c b c$ & $0.000^{c d c d}$ & $15.667^{\text {b b b b }}$ & $0.000^{\mathrm{ab} a \mathrm{a}}$ \\
\hline Verticillium dahlia & $0.000^{c c c c}$ & $0.000^{c d c c}$ & $0.000^{c d c d}$ & $0.000^{\text {dede }}$ & $0.000^{\text {baa }}$ \\
\hline $\operatorname{Pr}>\mathrm{F}$ & 0.000 & 0.000 & 0.000 & 0.000 & 0.348 \\
\hline Significant & Yes & Yes & Yes & Yes & No \\
\hline
\end{tabular}

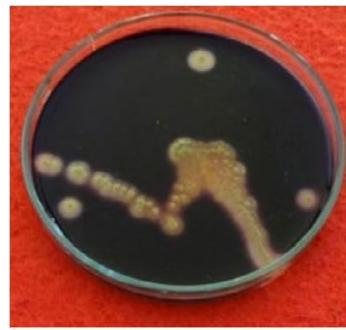

(i) Amylase

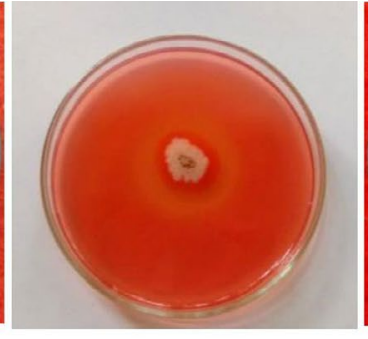

(ii) Cellulase

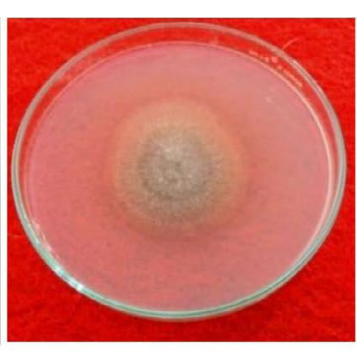

(iii) Lipase

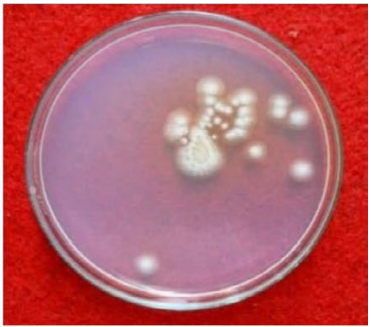

(iv) Protease

Fig. 4. Screening of endophytic fungi for enzyme production.
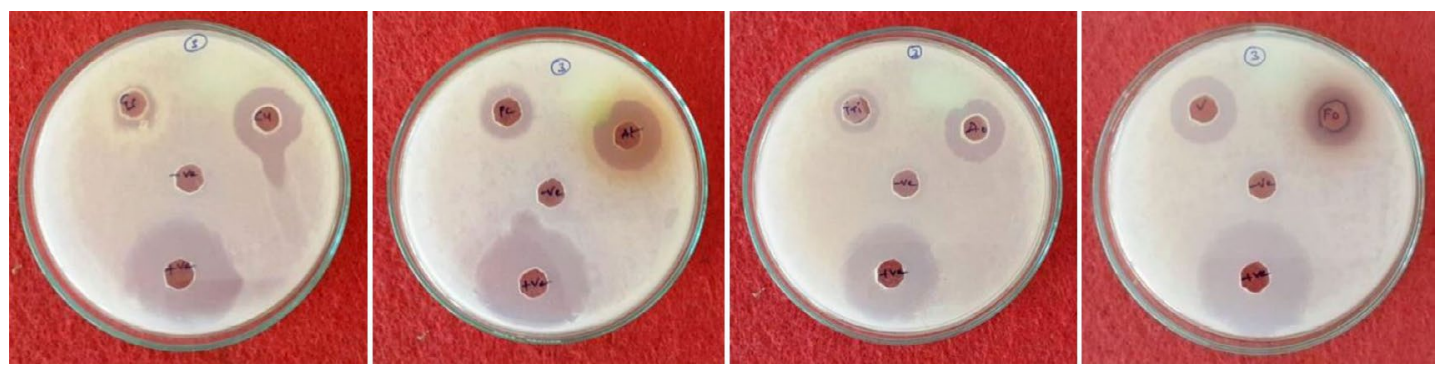

Fig. 5. Screening of endophytic fungi for Antimicrobial activity. 
none of the other fungi produced laccase. Mohini et al. $(2015)^{30}$ evaluated large number of endophytes isolated from various medicinal plants for various enzymes and found that they were capable to produce extracellular enzymes, though with variation. They inferred that variation in production of enzymes by endophytic fungi depends on the host and their ecological niches. Similar to present study, Uzma et al., (2016) and Sunitha et al. $(2013)^{32}$ reported that the same results correlated in the lack of laccase production in the endophytes studied by them. The extracellular enzymes produced by the endophytic fungus Rhizophora apiculata studied by Kumaresan and Suryanarayanan (2002) ${ }^{33}$.

Antimicrobial activity against fungi, bacteria and viruses was evaluated by so many investigators such as Maria et al. (2005) $)^{34}$ and Pavithra et al. (2012) ${ }^{35}$. The present work revealed that all the test fungi showed both antibacterial and antifungal activities. Antibacterial activity extended to Gram + ve and Gram - ve bacteria. However, they could not inhibit the bacterial growth significantly. Cuomo et al. (1915) ${ }^{36}$ reported a maximum number of antimicrobially active species were isolated from marine areas. Some endophytic species like Pestalotia were reported to produce antifungal metabolites ${ }^{37}$. "Dragfuss and Chapela (1994) ${ }^{38}$ considered fungal genera Acremonium, Aspergillus and Penicillium as 'creative species' for the production of variousand maximum number of bioactive compounds". Cultural conditions influence the growth of fungi, which in turn may affect the secondary

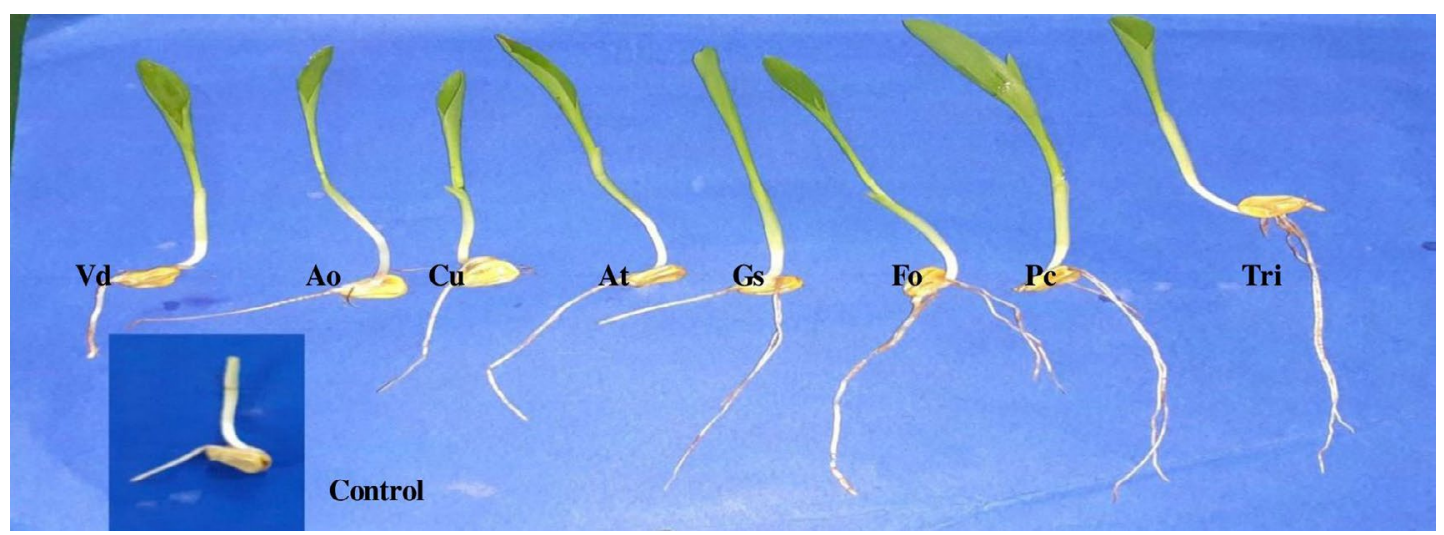

Fig. 6. Influence of endophytic fungal extracts on root growth of maize seedings.

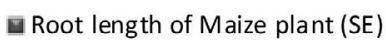

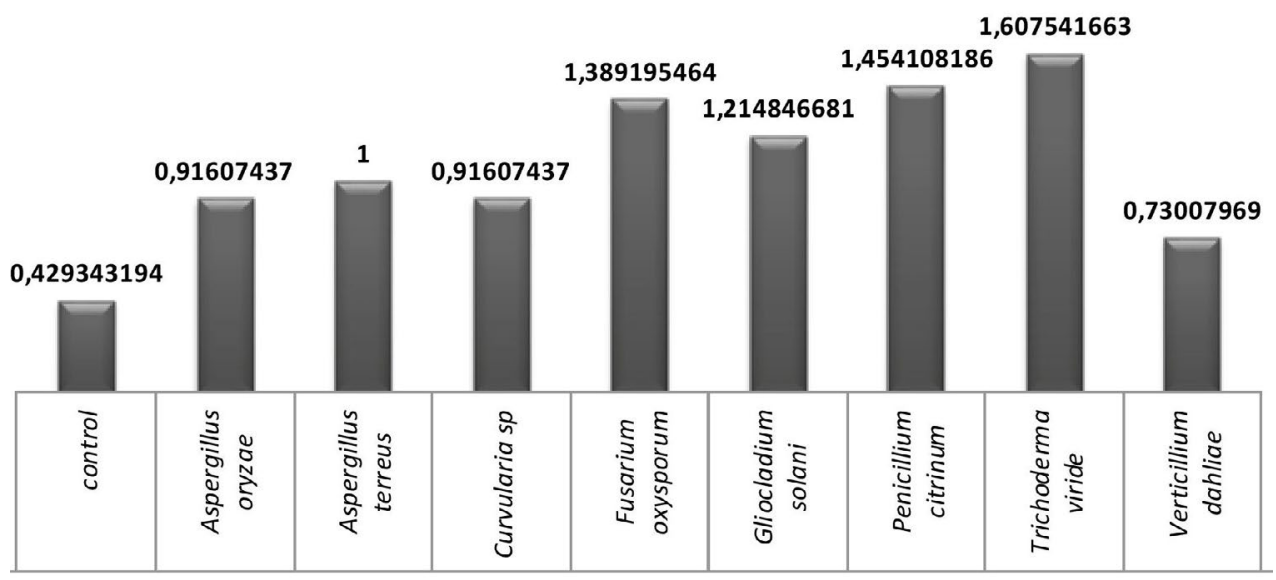

Fig. 7. Influence of endophytic fungal crude extracts on root growth of maize seedings. 
Table 4. Antimicrobial activity of isolated endophytic eungi

\begin{tabular}{|c|c|c|c|c|c|}
\hline & \multicolumn{5}{|c|}{ Zone of inhibition $(\mathrm{mm})^{2}$} \\
\hline & SA & ML & ST & $\mathrm{KP}$ & $\mathrm{CA}$ \\
\hline Control & $33.667^{\text {a a a }}$ & $35.667^{\text {a a a a }}$ & 32.000 а а а & $26.333^{\text {а а а а }}$ & $25.667^{\text {а а а а }}$ \\
\hline Aspergillus terrieus & 23.333 a ab a ab & 25.667 a ab a ab & 20.333 a ab a ab & 25.000 a а а & $20.333^{a}$ ab ab ab \\
\hline Curvularia sp. & 18.667 aba ab & 24.000 a ab a ab & $21.333^{a}$ ab a ab & 23.667 a а a & 14.000 ab b abc ab \\
\hline Fusarium oxysporum & $27.333^{\text {a ab a ab }}$ & 23.667 a ab a ab & 16.667 a bab ab & $0.875^{\text {a a a }}$ & 13.667 ab b abc ab \\
\hline Penicillium citrinum & $21.667^{\text {a ab a ab }}$ & 24.667 a ab a ab & 15.667 ab b ab b & 0.792 а а а & 19.000 ab ab ab ab \\
\hline Gliocladium solani & $0.792^{\text {ba ab }}$ & 26.667 a ab a ab & 12.000 ab b ab b & 14.667 ab a ab a & 16.667 ab ab ab ab \\
\hline Aspergillus oryzae & $17.333^{a b a b b}$ & $21.667^{\text {a ba ab }}$ & 0.750 ab a ab & $20.667^{\text {а а а а }}$ & $0.000 \mathrm{bccbcc}$ \\
\hline Trichoderma viridae & 17.333 ababb & $15.000 \mathrm{ab} b a b b$ & 13.667 ab bab b & 16.333 ab a ab a & $12.333^{a b c b a b c b}$ \\
\hline Verticillium dahliae & $0.000^{b c b c}$ & $0.000^{b c b c}$ & $0.000^{b c b c}$ & $0.000^{\text {bb b }}$ & $0.000 \mathrm{cccc}$ \\
\hline $\operatorname{Pr}>\mathrm{F}$ & 0.000 & 0.000 & 0.000 & 0.000 & 0.000 \\
\hline Significant & Yes & Yes & Yes & Yes & Yes \\
\hline
\end{tabular}

*SA = Staphylococcus aureus $* \mathrm{ML}=$ Micrococcus luteus $* \mathrm{ST}=$ Salmonella typhi

${ }^{*} \mathrm{KP}=$ Klebsiella pneumonia ${ }^{*} \mathrm{CA}=$ Candida albicans

Table 5. Production of IAA by selected eight fungal endophytes

\begin{tabular}{|c|c|c|}
\hline Endophytic fungi & $\begin{array}{l}\text { Medium without } \\
\text { tryptophan }(\mu \mathrm{g} / \mathrm{ml})\end{array}$ & $\begin{array}{c}\text { Medium with } \\
\text { tryptophan }(\mu \mathrm{g} / \mathrm{ml})\end{array}$ \\
\hline Trichoderma viridae & $63.667^{\text {а аа а }}$ & $70.333_{\text {аа а }}$ \\
\hline Aspergillus terrieus & 54.333 a a aba & 60.667 ab a ab a \\
\hline Gliocladium solani & $49.333^{a b a b a}$ & 57.000 ab a ab a \\
\hline Fusarium oxysporum & 48.667 ab a ab a & 56.000 ab a ab a \\
\hline Curvularia sp. & 44.333 ab a ab a & 52.667 ab a ab a \\
\hline Aspergillus oryzae & 39.333 ab a aba & 47.000 ab a abca \\
\hline Penicillium citrinum & 33.667 abc a abca & 41.333 abc a abca \\
\hline Verticillium dahliae & $0.000 \mathrm{cbcb}$ & $0.000 \mathrm{cbcb}$ \\
\hline Control & $0.000^{b c b b c b}$ & $0.000^{b c b b c b}$ \\
\hline $\operatorname{Pr}>\mathrm{F}$ & 0.000 & 0.000 \\
\hline Significant & Yes & Yes \\
\hline
\end{tabular}

Table 6. Ammonia production and phosphate solubilization of endophytic fungi

\begin{tabular}{cccc}
\hline No. Endophytic fungi & $\begin{array}{c}\text { Ammonia } \\
\text { production }\end{array}$ & $\begin{array}{c}\text { Phosphate } \\
\text { solubilization }\end{array}$ \\
\hline & control & - & - \\
2 & Aspergillus oryzae & +++ & ++ \\
3 & Aspergillus terreus & ++ & +++ \\
4 & Curvularia sp. & +++ & + \\
5 & Fusarium oxysporum & + & ++ \\
6 & Gliocladium solani & + & +++ \\
7 & Penicillium citrinum & + & ++ \\
8 & Trichoderma viride & +++ & +++ \\
9 & Verticillium dahliae & ++ & - \\
\hline
\end{tabular}

metabolites production. Fermentation conditions may also influence the production of antimicrobial compounds.

Fungal endophytes are reported to influence the host plant growth through transport of nutrients and / or by direct production of or stimulating the production of plant growth hormones ${ }^{39}$. Plants harboring endophytic fungi which exhibit enhanced growth over those without fungal endophytes due to activities of fungi which may include solubilization of phosphates, production of IAA, and mobilizing scarcity of soil nutrients ${ }^{40,41,42}$. In the present work it has been examined that all the eight test fungi produced 
$I A A$, and released ammonia and phosphate solubilizing enzymes. However, a significant variation has been observed among the species. For example, V. dahliae could not produce IAA and phosphate solubilizing enzymes. Mehmood et al. $(2018)^{43}$ reported that IAA producing endophytic fungus Fusarium oxysporum promotes the maize growth under hydroponic conditions.

According to Zhang et al. (2011) ${ }^{44}$ various endophytic fungi having various capacities to produce IAA. The present study also reveals that extracts of eight endophytic fungi enhanced root length to a significant level over the untreated plants.

\section{CONCLUSIONS}

The present investigations reveal that eight endophytic fungal species are able to produce extracellular enzymes. However, the potentiality differed with fungi. Endophytic fungi are poor producers of laccase, as has been reported in other studies also. This study also substantiates the report of various other workers in the field that endophytic fungi are repoirters of antimicrobial metabolites. Further studies are required to select efficient strains by subjecting them to vigorous screening methods. Further, there is a need to screen the crude and purified extracts for screening against a large number of microorganisms including viruses. These studies also revealed that fungal endophytes enhance plant growth by producing a range of metabolites. Hence, these endophytes can be exploited in agriculture field after proper selection, and testing against the different plants. Further studies are required to identify the chemical nature of metabolites from fungal endophytes and their specific biological activities. Our future studies will be in this direction.

\section{ACKNOWLEDGEMENT}

The authors express their sincere thanks to Head, Department of Botany, Kakatiya University for encouragement and facilities. We are thankful to Dr. S. Ram Reddy, Emeritus professor (UGC) for critical suggestions in the preparation of manuscript.

\section{CONFLICTS OF INTEREST}

The authors declare that there is no conflict of interest.

\section{AUTHORS' CONTRIBUTIONS}

All authors listed have made a substantial, direct and intellectual contribution to the work, and approved it for publication.

\section{FUNDING}

This work was supported by the UGC, New Delhi in the form of Rajiv Gandhi National Fellowship (F1-17.1/2016-17/RGNF-2015-17-SCTEL-25058).

\section{DATA AVAILABILITY}

All datasets analyzed during this study are included in the manuscript.

\section{ETHICS STATEMENT}

Not applicable

\section{REFERENCES}

1. Schulz B, Boyle C. The endophytic continuum. Mycol. Res. 2005; 109: 661-686. doi: 10.1017/ S095375620500273X

2. Tuangporn P, Prakitsin S, Jittra P, Polkit S, Aphichart K. Screening and production of Lipase from Endophytic fungi. The $12^{\text {th }}$ Khan Kaen University Graduate Research Conference; 2011.

3. Arnold AE. Understanding the diversity of foliar endophytic fungi: progress, challenges, and frontiers. Fungal Biol. Rev. 2007; 21: 51-66. doi: 10.1016/j. fbr.2007.05.003

4. Strobel G. Microbial gifts from rain forests. Canadian J Plant Pathol. 2002; 24: 14-20. doi: 10.1080/07060660109506965

5. Prabavathi D, Valli Nachiyar C. Screening for extracellular enzymes and production of cellulase by an endophytic Aspergillus sp, using Cauliflower stalks as substrate. International Journal on Applied Bioengineering, 2012;6(2):40-45. doi: 10.18000/ ijabeg. 10098

6. Strobel GA. Endophytes as sources of bioactive products. Microbes and Infection. 2003; 5: 535-544. doi: 10.1016/S1286-4579(03)00073-X

7. Suryanarayanan TS, Thirunavukkarasu N, Govindarajulub MB, Sasse F, Jansen R, Murali TS. Fungal endophytes and bioprospecting. Fungal Biol. Rev. 2009; 23: 9-19. doi: 10.1016/j.fbr.2009.07.001

8. Tan RX, Zou WX. Endophytes: a rich source of functional metabolites. Nat Prod Res. 2001; 18:448-459. doi: 10.1039/b100918o

9. Correa RCG, Rhoden SA, Mota TR, et al. Endophytic fungi: expanding the arsenal of industrial enzyme 
producers. J. Ind.Microbiol. Biotechnol. 2014; 41(10): 1467-1478.

10. Bal HB, Subhasis D, Tushar KD, Tapan KA. ACC deaminase and IAA producing growth promoting bacteria from the rhizospere soil of tropical rice plant. Basic Microbiol. 2013; 53(12): 972-984. doi: 10.1002/ jobm.201200445

11. Chatterji A, Pakrashi S. The Treatise of Indian Medicinal Plants. New Delhi: Publications \& Information Directorate. 1994; p 107.

12. Petrini O. Taxonomy of endophytic fungi of aerial plant tissues. In: Fokkema NJ, Van Den Heuvel eds. Microbiology of the phyllosphere, Cambridge, UK, Cambridge University press, 1986; p 175.

13. Hallmann J, Berg G, Schulz B. Isolation procedure for endophytic microorganisms. Berlin Heildberg: Springer. 2004; p 299. doi: 10.1007/3-540-33526-9_17

14. Selvanathan $S$, Indrakumar I, Johnpaul M. Biodiversity of the endophytic fungi isolated from Calotropis gigantean (L.) R.Br. Recent Res Sci Technol. 2011; 3: 94-100.

15. Barnett HL, Hunter BB. Illustrated Genera of Imperfect Fungi, New York: Macmillan Publishing Company: 1987.

16. Hankin L, Anagnosakis SL. The use of solid media for detection of enzyme production by fungi. Mycologia. 1975; 67: 597-607.

17. Radji M, Sumiati A, Rachmayani, R, Elya B. Isolation of fungal endophytes from Garcinia mangostana and theirantibacterial activity. African Journal of Biotechnology. 2011; 10(1): 103-107.

18. LvYL, Zhang FS, Chen J, et al. Diversity and antimicrobial activity of endophytic fungi associated with the alpine plant Saussurea involucrata. Biol. Pharm. Bull. 2010; 33(8):1300-1306. doi: 10.1248/bpb.33.1300

19. Ratul Nath G. Sharma D, Madhumita B. Efficiency of Tricalcium Phosphate Solubilization by Two Different Endophytic Penicillium sp. Isolated from Tea (Camellia sinensis L.). European Journal of Experimental Biology. 2012; 2 (4):1354-1358.

20. Singh $\mathrm{P}, \mathrm{Kumar} \mathrm{V}$, Agarwal S. Evaluation of phytase producing bacteria for their plant growth promoting activities. Int. J. Microbiol. 2014; 426-483. doi: $10.1155 / 2014 / 426483$

21. Reversat G, Boyrt J, Sannier C, Pando-bahuon A. Use of mixture of sand and water - absorbent synthetic polymer as substrate for the xenic culturing of plantparasitic nematodes in the laboratory. Nematology. 1999; 1: 209-212. doi: 10.1163/156854199508027

22. Ahmed F, Ahmad I, Khan MS. Indole acetic acid production by indigenous isolates of Azatobacter and flurescent Pseudomonas in the presence and absence of tryptophan. Turk.J. Biol. 2005; 29: 29-34.

23. Fouda AH, Hassan SED, Eid AM, Ewais EED. Biotechnological applications of fungal endophytes associated with medicinal plant Asclepias sinaica (Bioss.) Annals of Agricultural Sciences. 2015; 60: 95104. doi: 10.1016/j.aoas.2015.04.001

24. Beltrán-Nambo MdlA, Martínez-Trujillo M, MonteroCastro JC, Salgado-Garciglia R, Otero-Ospina JT, Carreón-Abud $Y$. Fungal diversity in the roots of four epiphytic orchids endemic to Southwest Mexico is related to the breadth of plant distribution. Rhizosphere. 2018; 7:49-56. doi: 10.1016/j. rhisph.2018.07.001

25. Arora P, Wani ZA, Ahmad T, Sultan P, Gupta S, Riyaz-UI-Hassan S. Community structure, spatial distribution, diversity and functional characterization of culturable endophyticfungi associated with Glycyrrhiza glabra L. Fungal Biol. 2019 ;123:373-383. doi: 10.1016/j.funbi o.2019.02.003

26. Mehmood A, Hussain A, Irshad M, et al. Cinnamic acid as an inhibitor of growth, flavonoids exudation and endophytic fungus colonization in Maize root. Plant Physiol Biochem. 2019; 135:61-68. doi: 10.1016/j. plaph y.2018.11.029

27. Pan F, Su TJ, Cai SM, Wu W. Fungal endophyte-derived Fritillaria unibracteata var. wabuensis: diversity, antioxidant capacities in vitro and relations to phenolic, flavonoid or saponin compounds. Sci. Rep. 2017; 7: 42008. doi: 10.1038/srep42008

28. Mousa WK, Schwan A, Davidson J, et al. An endophytic fungus isolated from finger millet (Eleuseine coracana) produces anti-fungal natural products. Front Microbial. 2015; 6: 1157. doi: 10.3389/fmicb.2015.01157

29. Suryanarayanan TS, Thirunavukkarasu N, Govindarajulub MB, Gopalan V. Fungal endophytes: an untapped source of biocatalysts. Fungal Diverse. 2012; 54(1): 19-30. doi: 10.1007/s13225-012-0168-7

30. Patil MG, Pagare J, Patil SN, Sidhu AK. Extracellular enzymatic activities of endophytic fungi isolated from various medicinal plants. Int.J.Curr.Microbiol.App.Sci. 2015;4(3):1035-1042

31. Uzma F, Konappa NM, Chowdappa S. Diversity and extracellular enzyme activities of fungal endophytes isolated from medicinal plants of western Ghats, Karnataka. Egyptian J. of Basic and Applied Sci. 2016; 3: 335-342. doi: 10.1016/j.ejbas.2016.08.007

32. Sunitha VH, Devi D, Nirmala, Srinivas C. Extracellular enzymatic activity of endophytic fungal strains isolated from medicinal plants. World J. Agric. Sci. 2013; 9(1): $1-9$.

33. Kumaresan V and Suryanarayanan TS. Endophyte assemblage in young, mature and senescent leaves of Rhizophora apiculata: evidence for the role of endophytes in mangrove litter degradation. Fungal Diversity. 2002; 9: 81-91.

34. Maria GL, Sridhar KR, Raviraja NS. Antimicrobial and enzyme activity of mangrove endophytic fungi of southwest coast of India. J Agri Tech. 2005; 1: 67-80.

35. Pavithra N, Sathish L, Ananda K. Antimicrobial and enzyme activity of endophytic fungi isolated from Tulsi. Journal of Pharm and Biomed. Sci. 2012; 16(12):1-9.

36. Cuomo V, Palomba I, Perretti A, Guerriero AD' Ambrosio M, Pietra F. Antimicrobial activities from marine fungi. Journal of Marine Biotechnology. 1995; 2: 199-204.

37. Strobel G, Ford E, Worapong J, et al. Isopestacin, an isobenzofuranone from Pestalotiopsis microspora possessing antifungal and antioxidant activities. Phytochemistry. 2002; 60: 179-183. doi: 10.1016/ S0031-9422(02)00062-6

38. Dreyfuss MM, Chapela IH. Potential of fungi in the discovery of novel, loe-molecular weight 
pharmaceuticals. In: The discovery of Natural Products with therapeutic potential (ed Gullo VP.). ButterworthHeinemann, Boston. 1994; 49-80. doi: 10.1016/B9780-7506-9003-4.50009-5

39. Kei H, Nina G, Soledad S, et al. Root endophyte Colletotrichum tofieldiae confers plant fitness benefits that are phosphate status dependent. Cell. 2016; 165 (2): 464-474. doi: 10.1016/j.cell.2016.02.028

40. Priyadharsini P, Muthukumar T. The root endophytic fungus Curvularia geniculata from Parthenium hysterophorus roots improves plant growth through phosphate solubilization and phytohormone production. Fungal Ecol. 2017; 27: 69-77. doi: 10.1016/j.funeco.2017.02.007

41. Tsavkelova EA, Cherdyntseva TA, Botina SG, Netrusov Al. Bacteria associated with orchid roots and microbial production of auxin. Microbiol. Res. 2007; 162: 69-76. doi: 10.1016/j.micres.2006.07.014
42. Khan AL, Hamayun M, Kan SM, Kim YH, Jung HY. Endophytic fungal association via gibberellins and indole acetic acid can improve plant growth under abiotic stress: an example of paecilomyces formosus LHL10. BMC microbiology. 2012; 12:3. doi: 10.1186/1471-2180-12-3

43. Asif M, Irshad M, Nayeem Khan, et al. IAA producing endophytic fungus Fusarium oxysporum w/w colonize Maize Roots and promoted Maize growth under hydroponic condition. Eur Exp Biol. 2018;8(4): 24

44. Zhang $Y$, He L, Chen Z, Wang, Q, Quin M, Sheng $X$. Characterization of ACC deaminase-producing endophytic bacteria isolated from copper-tolerant plants and their potential in promoting growth and copper accumulation of Brassica napus. Chemosphere. 2011; 83: 57-62. doi: 10.1016/j. chemosphere.2011.01.041 